J. Dairy Sci. 95:6830-6830

http://dx.doi.org/10.3168/jds.2012-95-11-6830

(C) American Dairy Science Association ${ }^{\circledR}, 2012$.

\title{
Erratum to "Effect of increasing oil from distillers grains or corn oil on lactation performance" (J. Dairy Sci. 88:2820-2827)
}

\section{Leonardi, S. Bertics, and L. E. Armentano}

Table 4 (page 2826) contained incorrect data for milk fatty acids C10:0, C12:0, and C14:0. In the original published table, numerical data for C10:0 were inadvertently omitted, resulting in an upward shift of data rows. Thus, C12:0 data were mistakenly reported as C10:0 data, C14:0 data as C12:0 data, and sum of C4:0 through C12:0 were reported as C14:0 data. Corrected data for C10:0, C12:0, and C14:0 are reported below.

The authors regret the error.

Table 4. Treatment effect on milk fatty acid profile

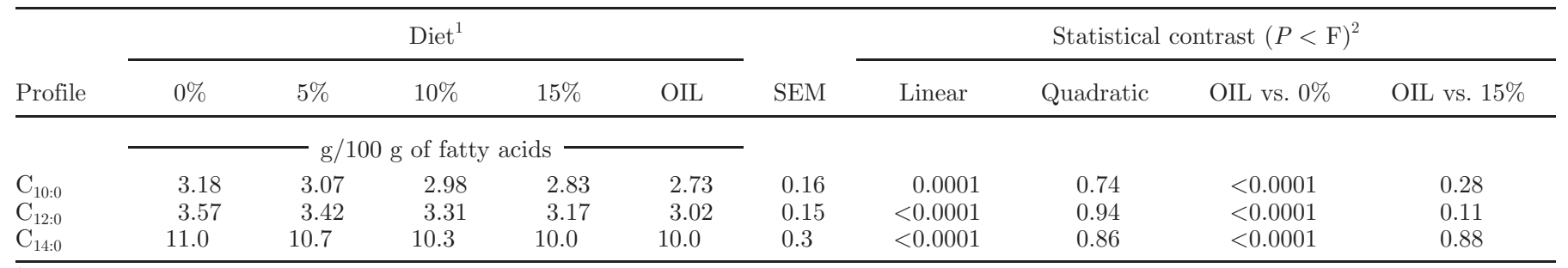

${ }^{1}$ Diets: $0,5,10$, or $15 \%$ DGS = diets containing distillers dried grains with solubles (DGS, DM basis); OIL = diet containing corn oil but no DGS; the amount of corn oil added was such that OIL and 15\% DGS had similar total fatty acid concentration.

\section{REFERENCES}

Leonardi, C., S. Bertics, and L. E. Armentano. 2005. Effect of increasing oil from distillers grains or corn oil on lactation performance. J. Dairy Sci. 88(8):2820-2827. 